This is a pre-copyedited version of a contribution published in:

01vera-Lobo, M. D. ; Gutiérrez-Artacho, J. (2017). "Web

localization: the Spanish SMEs as case of study". 12th Iberian

Conference on Information Systems and Technologies (CISTI), 21-24

de junio, Lisboa (Portugal). IEEE, pp. 1-6, D0I:

10.23919/CISTI. 2017.7975872. The definitive authenticated version

is available online via

https://ieeexplore. ieee. org/document/7975872

\title{
Web localization: the Spanish SMEs as case of study
}

\author{
María-Dolores Olvera-Lobo \\ Department of Information and Communication \\ University of Granada, UGR \\ Granada, Spain \\ molvera@ugr.es
}

\author{
Juncal Gutiérrez-Artacho \\ Department of Translation and Interpreting \\ University of Granada, UGR \\ Granada, Spain \\ juncalgutierrez@ugr.es
}

\begin{abstract}
Constant changes in the economic environment, where globalization and the development of the knowledge economy act as drivers, are systematically pushing companies towards the challenge of accessing external markets. Web localization constitutes a new field of study and professional intervention. From the translation perspective, localization equates to the website being adjusted to the typological, discursive and genre conventions of the target culture, adapting that website to a different language and culture. This entails much more than simply translating the content of the pages. The content of a webpage is made up of text, images and other multimedia elements, all of which have to be translated and subjected to cultural adaptation.
\end{abstract}

A case study has been carried out to analyse the current presence of localization within Spanish SMEs from the chemical sector. Two types of indicator have been established for evaluating the sample: indicators for evaluating company websites and indicators for evaluating web localization.

Upon analysing the usage and quality of the websites of SMEs from the chemical sector in Spain, we have observed that $61 \%$ of them do not have the technology necessary to correctly access the website from any mobile device. SMEs that employ a more advanced use of their websites have been able to apply the advantages offered by web localization in another language, as this affords greater internationalization and globalization.

Keywords - Web localization, enterprises, internationalization, Spanish SMEs, chemical sector

\section{INTRODUCTION}

Localization forms part of the group of interdependent processes known by the acronym GILT: Globalization, Internationalization, Localization, Translation [1]. Observed individually it can be established that translation is a process by which the meaning of a written text in a source language is communicated through an equivalent text in the target language. Regarding localization, the most popular definition, put forward by the now disappeared Localization Industry Standard Association (LISA), maintains that this activity involves taking a product and making it linguistically and culturally appropriate for a locale, that is, the country and target language in which the specific product will be used and sold [2]. LISA states that in the localization process the linguistic, content/cultural, physical and technical issues are implicated. Therefore, the languages involved must be taken into account, but also the currencies, symbols or culture, transferring the message to another linguistic and culturally different public. In fact, culture adaptation in software products or web text is one of the most important localization factors [3]

Internationalization is an attempt to give visibility to the information contained by the company. It has the objective of focusing on the development stage of a product that does not depend on the language that determines. The "internationalised text" is a beginning for localizations into the maximum possible number of languages possible [4]. Thus, internationalization consists in identifying all local information that appears on a website, that is, that information that is dictated by the language and culture of the country where it was originally designed, for example, dates, numbers, currency, contact information, among others. These elements must be 
isolated and saved independently so they can be adapted to the specifications of any language.

Lastly, globalization combines the processes of internationalization and localization. It consists of the design of websites that can be used in different countries with a minimum of changes. It is a concept that belongs more to the marketing than the technical department. At present, globalization takes in processes broader than localization, facilitating product distribution or multilingual help to clients [5].

Beside the localization of software, videogames and apps, amongst others, in the last few years we have witnessed the unprecedented growth of web localization, a communicative, technological, textual and cognitive process by which interactive digital texts (or websites) are modified for use by an international public which is not the use initially foreseen [6]. The localization of web content includes several sub-processes take place whose nature differs according to the context or intention. Different professional profiles intervene in the translation-localization process.

Translation professionals make up one of the basic axes of inter-linguistic mediation [7]. Professional translation environments might currently be ruled by conflict, opacity and mistrust between translators and direct clients or managers, due to the computer-mediated nature of communication and of translation production networks $[8,9]$. Web localization is often the last stage before content is published [10] and, depending on the process, it may happen that localizers do not have the freedom or the possibility to make the changes necessary to adequately adapt the content to their markets [11].

The interaction and collaboration of the translator-localizer team with other professionals should be sought, constituting an extensive group of different professionals. Every step in the localization process is taken and decisions are made in accordance with the coordination of an extensive team work. The team members may include a project manager, desktop publisher, localization engineer, graphic designer, and technical expert to translator in action, linguists and other senior translators to revise the localization project [12].

From a translation perspective, localization would be the equivalent of a website adjusting to the typological, discussion and gender conventions specific to the target language, adapting the website in question to a different language and culture. This means much more than simply translating the content of the pages. The content of a web page is made up of text images and other multimedia elements, all of which need to be translated and subject to cultural adaptation. Users should never notice that the site was originally created in another language. Additionally, commercial and business translation has a number of particularities that must necessarily be studied and taken into account in order to achieve the desired communication aims [13-14].

The success of websites as global communication platforms, the exchange of information or the selling of products and services has been pronounced in the development of localization processes, closing the gap between Internet users from different socio-cultural and linguistic contexts. The economic importance of this phenomenon is increasing, and its significance is borne out by the growing body of research dedicated to localization, specialized conferences and the number of institutions offering training courses for professionals in this area.

The internationalization and localization of websites are complex and costly processes, to which many businesses are reluctant to implement them. The long-term benefits, however, far outweigh initial costs as they suppose the creation of new markets, an increase in sales, a simplification of the process of updating information and a greater speed in entering new markets, amongst other advantages [15]. The continuous process of change in the economic environment, where the acceleration of the globalization process and development of the knowledge economy are driving forces, is systematically pushing businesses towards the challenge that facing foreign markets poses. Web localization is essential for businesses for promotion in different markets. For example, one product that is going to be sold in Hungary is different to one in South American countries because there are totally different terms or symbols which could offend due to a different concept of a word, image or colour. The web localization process is understood as an adaptation procedure.

For this reason it is said that websites, more than being translated, are localized, because they are translated to a language but adapted to everything else. This contemplates almost a need for survival on the part of companies. Internet visibility is not the sole factor but it is a very relevant one.

\section{SMES ON THE WEB: THE CASE OF SPAIN}

The Strategic Plan for Internationalization and Priority Markets (2014-2015) elaborated every two years by the Spanish Ministry of Economy and Competitiveness, within the Inter-ministry Group for Support for the Internationalization of Spanish Businesses, and with the participation of the private sector and the Autonomous Regions, has the main objective of driving the internationalization of the Spanish economy, improving its competitiveness and favouring the global presence of Spanish businesses, thus contributing to the implementation of a new model of economic growth for Spain orientated towards the exterior. Nevertheless, in relation to ecommerce and its online presence, Spanish companies still have a long way to go. In accordance with a recent report carried out by the Nominalia hosting company (www.nominalia.com) in 2015, 36.20\% of Spanish companies still lack a corporate website, although $22.41 \%$ are in possession of one or more domains while awaiting the creation of their website. Interestingly, the same study reveals how $89.6 \%$ of users consider it essential for a company to have a web presence, even if it is just for questions of image and trustworthiness. Another report carried out by the Nominalia hosting company in 2016 confirms that only $35.20 \%$ of Spanish companies make SEO process, in spite of that $45.40 \%$ of Spanish companies requested state the major benefit that a website can be provided to the companies is the visibility.

Small and medium-sized enterprises (SMEs) are especially vulnerable in this changing environment. The microenterprises 
and SMEs are the motor of European Economy, since they promote job creation and economic growth, as well as ensuring social stability. By 2013, more than 21 million SMEs provided 88.8 million of jobs throughout the European Union (EU) [16]. The category of SMEs is defined by the European Commission as having less than 250 persons employed. They should also have an annual turnover of up to EUR 50 million, or a balance sheet total of no more than EUR 43 million [17].

$99.70 \%$ of Spanish companies (SMEs and large companies) had access to the Web [18]. However, the online presence through a corporate website reached $76.7 \%$ of the companies and this varied depending on their size and business sector. SMEs are conscious of the fact that, as well as having a presence on the internet, it must be frequently optimized and maintained. Today, $57.30 \%$ already had their own website in 2016. [19] Any business without a website will not be found on one of the most powerful marketing tools available to it. A website affords credibility and, furthermore, helps to show the success of a company. A website is also much easier to update information on its products and services than a printed brochure or catalogue. Thus, it is a good way to inform users of the new arrival of products, services, events, deals, etc. that can be offered to them.

The main challenge of SMEs is to improve web portals optimizing them for mobiles -only $26 \%$ of SMEs have services optimized for mobile devices [19]-, SEO, making company videos or creating forums. Furthermore, companies with a social network presence enjoy a greater increase in sales. That is why $67.40 \%$ of SMEs consider that companies without a social network profile will be left behind technologically. In terms of the presence of the company on social networks, there has been a considerable increase over the last three years. The most accepted social network is Facebook.

Starting out from this reality and the fact that the translation and localization of websites contribute towards promoting the launch towards foreign markets of Spanish SMEs, Web localization constitutes a new area of study.

According to the data of the Annual Spanish National Accounts, Chemical Industry is the third largest industrial sector of the Spanish economy reached 15.533 million Euros in 2014 , representing $12.40 \%$ of the total added value from manufacturing industry. This data places Chemical Industry as the third largest industrial sector for its contribution to GDP, as the same that the metallurgical sector $(12.04 \%)$, and only behind food industry and transport and automobiles [20].

Sales by the Spanish chemical sector totalled $€ 58,056$ million in 2015, a rise of 3\% over 2014 and $16.70 \%$ since 2007 -the year that the crisis began-compared to a $24 \%$ contraction in sales recorded by Spain's combined industrial sectors. Foreign markets, which account for $56.50 \%$ of sales, were once again the main driver of growth in the sector, with exports increasing by $2.5 \%$ to $€ 32,774$ million compared to 2014 and $43.30 \%$ higher than in 2007 [20].

The Spanish chemical sector, which consists of more than 4,014 companies -of which $96 \%$ are SMEs- currently generates 540,000 direct, indirect and induced jobs. In addition to strong export capabilities, its competitiveness also lies in its capacity for innovation and technology, accounting for $24.90 \%$ of all $\mathrm{R} \& \mathrm{D}+\mathrm{i}$ investments made by Spanish industry as a whole and employing $21.10 \%$ of all research personnel in industrial companies [20]. These characteristics make it a strategic, competitive and international sector.

This study analyses the degree to which Spanish Chemical SMEs are implementing their web localization to guarantee their presence in other markets. The quality of e-commerce is not measured, rather simply the information about service and products they offer.

\section{METHODOLOGY}

A pilot study has been carried out to analyse the current presence of the web localization in chemical Spanish SMEs. The initial study sample included the spanish chemical sector SMEs which are award-winning in 2015, and those presents in the DMOZ directory. The award-winning companies were recognised by FEIQUE (Business Federation of the Spanish Chemical Industry) in its 1st RSE (Corporate Social Responsibility) Awards, and by the DHL Atlas Export Awards 2015.

FEIQUE, in collaboration with the Spanish Chemical Forum and Society, celebrated its $1^{\text {st }}$ RSE Awards in Chemical Sector. Its Awards recognized the engagement of 17 Chemical companies in the principles of Corporate Sustainability and Social Responsibility. The Awards were divided in 14 categories and gathered in 4 areas: social, environment, economy and transparency, and Good Governance. They were awarded unanimously by a jury to 17 companies, SMEs and important companies of Chemical sector [21].

Also the second selection of companies was selected in the 2015 DHL ATLAS Awards Edition. The winners were three SMEs: Certest Biotech (Export Grand Award), XTraice (Award for Most sustainable Export) and AGQ Labs (Award for Most Innovative Export). AGQ Labs is the only SMEs in Chemical sector, it was awarded this prize for the innovation in its structure of services and solutions through biotechnology and analytical chemistry [22].

We have selected mainly the Chemical companies in the web directory DMOZ [23], also called Open Directory Project. It is the largest, most comprehensive human-edited directory of the Web. It is constructed and maintained by a global community of volunteer editors. These citizens can each organize a small portion of the web and present it back to the rest of the population, culling out bad content and adding just the best content. It can be considered as a relevant, reliable information source. DMOZ has a high page rank because Google have trust in the review of the editor. Google believes that the websites listed on DMOZ are useful and informational. Therefore, site listed in DMOZ will be given priority in most cases.

In this second phase of our selection we have used the search engine of the Spanish economic journal Expansion [24] to establish what companies selected in the first phase could be considered as a SME. Only two of the first Awards and one of the second were selected as part of our sample. The rest of

Research Project CSO2015-64532. Spanish "Ministry of Science and Innovation" and FEDER Program of the European Union. 
SMEs selected in our research were obtained in the "BussinessChemicals-Spain" category of DMOZ directory.

All of these companies had a size of between 50 and 249 employees and a turnover higher than $€ 50$ million. For the definitive sample selection only those with a website were selected: 31 out of the total number.

Two types of indicator have been established for evaluating the sample: indicators for evaluating company websites and indicators for evaluating web localization.

The first ones focus on the quality of the websites. We have developed a checklist based on the methodology proposed by Chua et al. [25]. Chua and colleagues grouped its checklist into three dimensions: quality of the system, quality of the information, and quality of service. Quality of the system refers to the website functionality, made up of four indicators -ease of access, usability, capacity for response and design-. Quality of the information is related to the precision, reliability, coverage and ease of use. Finally, Quality of service measures the empathy, interactivity, site 'happiness' and aesthetic attractiveness.

They have been evaluated with a Likert scale from 0-4: 0 (no indicator shown), 1 (shows indicator very poorly), 2 (shows indicator poorly), 3 (shows indicator well) and 4 (the indicator is shown very well).

The overall level of quality of the websites was calculated from the values given to each one of the 12 indicators that comprise the three dimensions of quality (quality of the system, information and service) [25].

In the web localization evaluation, translated text is as important as adaptation to the locale. The criteria are based on three dimensions: visual level, navigational level and contact information level. Related to visual level, the indicators evaluated are the text -localized and translated parameters' text-, figures -if the figures, images, videos and tables has been also translated and localized-, segments -if the distribution of text's segments are the same structure in the different localized languages-, updates -if news, blogs, press releases have also been localized-, languages -if the text and updates are made equally for all the languages in which the website is located-, homogeneity -if different sections of the website are localized or some of them not-, and slogans -the slogan of a company identifies and publicizes the services or products offered so it is important to take care of this aspect in the website localization.

The navigational level takes into account the consistency in localization browsing the entire website through the different sections. Also the information contact level takes into account whether all the elements of contact and information about the company (maps, addresses, telephone numbers, examples, legal information, etc.) have been adequately adapted.

As for the previous evaluation, they have been measured on a more reduced Likert scale of $0-2$, because they involve a more specific type of characteristic: 0 (no indicator, not evaluated), 1 (indicator, poor) 2 (indicator, good).

\section{RESULTS}

In accordance with the result obtained, the overall quality with 2.5 points obtained is above the average 2 of the Likert scale of 0 to 4 . The higher rating has been obtained by the system quality with 2.9 , followed by information quality $(2.7$ points) and, lastly, service quality (1.9 points). In general, the quality of websites from the chemical sector is good in terms of the system. In terms of ease of access, the websites have acceptable results on the basis of a search via the name of the company in question. As regards the definition of usability according to the ISO 9241 regulation, it can be said that the websites in the chemical sector are effective, efficient and satisfactory, with which a product can reach the specific objectives for determined users within the sector (3.2 points).

Regarding the quality of service, particular attention may be drawn to social networks, which would form part of the "interactivity" dimension. Under half of the companies are active on the social networks. A mere $48 \%$ of websites use them and of these, only $15 \%$ allow the creation and publication of opinions and content. The social networks that most stand out are Facebook, Twitter, YouTube, Blogger, Skype, Instagram, amongst others.

The capacity for response was also correct (3.3 points), and the websites loaded quickly and provided navigation systems such as breadcrumbs, sitemaps, menu bars, etc. Lastly, within these assessment indicators, $39 \%$ of SMEs from the chemical sector use a technology that facilitates access from different devices such as mobile phones and tablets, amongst others. $69 \%$ employ RSS syndication technology that facilitates the notification of an update or publication of new information on the site.

In terms of web localization, $69 \%$ of SME websites in the chemical sector are localised in another language. Three aspects have been analysed: visual, navigational and localizational.

The localization aspect has the best rating, which means that the companies adapt the telephone number, cookie policy and address, amongst other aspects. This is followed by the navigation aspect and, finally, the visual aspect, which had the greatest number of indicators assessed.

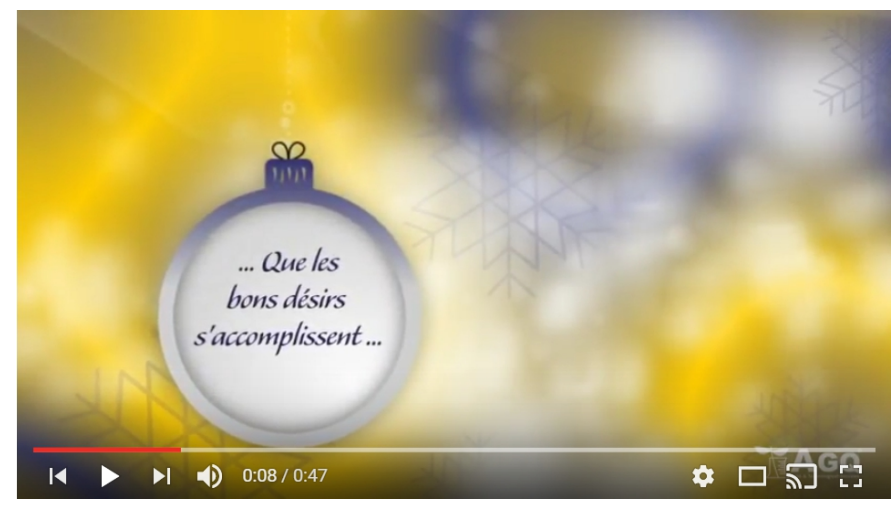

Figure 1. Example of localized video in 5 languages (English, French, Spanish, Italian and Portuguese) in the AGQ LABS' website 
The results of the case study reveal that in terms of the first analysis carried out the quality of the system and the quality of the information have a half-acceptable score on the websites evaluated, whereas in contrast the quality of the service does not reach a minimum acceptable score. With these results it is understood that Spanish SMEs pay less attention to the user because the websites analysed frequently do not offer services according to the user type, and the interactivity of the user within the website, amongst other aspects. It has also been demonstrated that in relation to design the large majority of SMEs do not present an option to access different devices such as tablets or mobiles.

\section{CONCLUSIONS}

The continuous transformation in the economic environment, where the acceleration of the globalization process and development of the knowledge economy are driving forces is systematically pushing businesses towards the challenge that entering foreign markets poses [26]. This study arises from this reality, and the fact that the translation and localization of websites contributes to the internationalization of SMEs, closing the gap between Internet users from different socio-cultural and linguistic contexts. Our aim is to visualise the importance of localization for the facilitation and improvement of the processes of externalization and globalization of Spanish SMEs. It is important to determine the most appropriate indicators in this context for measuring the quality of the localization of Spanish corporate SME websites from a technical and formal perspective, but also in terms of content (linguistic).

In this scenario, upon analysing the usage and quality of the websites of SMEs from the chemical sector in Spain, we have observed that $61 \%$ of them do not have the technology necessary to correctly access the website from any mobile device. Furthermore, the growing use of such devices makes it necessary to adapt this web content to Smartphones, as it would lead to a growth in clients and users. In addition, following the analysis of these websites, we have detected that both the informative content and the tools are out-of-date and obsolete.

However, the SMEs that employ a more advanced use of their websites have been able to apply the advantages offered by web localization in another language, as this affords greater internationalization and globalization. The companies that have their websites localised in another language are more internationally visible and as a result their products can reach any location without the website being an inconvenience, as it is correctly translated. However, it would be convenient for the companies lacking this tool to increase the presence of personnel qualified within the sphere of web localization and in the use of Web 2.0 tools. Following the assessment we can see that many companies are making great efforts to improve the localization of their websites.

As a final conclusion, it can be said that the survival of these companies in a globalised market is inextricably linked to the adaptation of informative content into a universal language such as English. These premises are key; they are needed from the point of view of information and communication for the survival of SMEs in international markets.

\section{ACKNOWLEDGMENT}

The authors are grateful to the Spanish "Ministry of Science and Innovation" for supporting this study, in the framework of the research Project CSO2015-64532-R, partially funded by the FEDER program of the European Union.

\section{REFERENCES}

[1] P. Cadieux and B. Esselink. GILT: Globalization, Internationalization, Localization, Translation. Globalization Insider, 11 (1.5): 1-5, 2004.

[2] LISA. Localization Industry Primer. Geneva: Localization Industry Standards Association, 2003.

[3] A. Lommel. The Globalization Industry Primer: An Introduction to preparing your business and products for success in international markets, 70. 2007.

[4] A. Pym. Localization from the Perpective of Translation Studies: Overlaps in the digital divide? Conferencia SCALLA 2004. 2004.

[5] M.A. Jiménez Crespo. El proceso de localización web: estudio contrastivo de un corpus comparable del género sitio web corporativo. Granada: Universidad de Granada. 2008.

[6] M. A. Jiménez-Crespo. Translation and Web Localization. New York: Routledge, 2013.

[7] M.D. Olvera-Lobo et al. "Translator Training and Modern Market Demands", in Perspectives: Studies in Translatology, vol. 20, no13, pp. 132-142, 2005.

[8] K. Abdallah and K. Koskinen, "Managing trust: Translating and the network economy", Meta: Journal des Traducteurs / Meta: Translators' Journal 52 (4), 673-687, 2007

[9] E. Alonso, "Conflict, opacity and mistrust in the digital management of professional translation projects". The International Journal of Translation and Interpreting Research 8 (1), 19-29, 2016.

[10] A. Herrmann and F. Sachse, "Internacionalización de aplicaciones de software". In Detlef Reineke (ed.), Traducción y localización. Mercado, gestión y tecnologías. 45-70. La Palmas de Gran Canaria: Anroart, 2007.

[11] E. de la Cova, "Translation Challenges in the Localization of Web Applications". Sendebar: Revista de la Facultad de Traducción e Interpretación, n. 27, pp. 235-266, 2016

[12] M. C. Odacioglu, "From Interdisciplinarity to Transdisciplinarity in Translation Studies in the Context of Technological Tools \& Localization Industry", International Journal of Comparative Literature \& Translaton Studies, Vol. 3, No. 3, 2015.

[13] P. Zhu. On the Right Strategies for Translating Business \& Technical Information. Journal of Education and Social Science 2 (1): 61-70, 2015.

[14] P. Zhu. Translation Criteria: How They May Affect International Business. Journal of Technical Writing and Communication 45 (3), 2015

[15] N. Corte. Localización e internacionalización de sitios web. Tradumática 2002.

[16] Comisión Europea, Dirección General de Mercado Interior, Industria, Emprendimiento y Pymes. Guía del usuario sobre la definición del concepto de pyme Luxemburgo: Oficina de Publicaciones de la Unión Europea, 2015.

[17] Comisión Europea. Reglamento (UE) n $n^{\circ}$ 651/2014 de la Comisión, de 17 de junio de 2014, por el que se declaran determinadas categorías de ayudas compatibles con el mercado interior en aplicación de los artículos 107 y 108 del Tratado. «DOUE» núm. 187, de 26 de junio de 2014, pp.1-78.

[18] ONTSI. La sociedad en red. Informe anual 2015. Observatorio Nacional de las Telecomunicaciones y la Sociedad de la Información. 2016. Available in: http://www.ontsi.red.es/ontsi/ 
[19] EBAY. Guía práctica de E-Commerce. 2016. Available in: https://www.aceleraconebay.com/sites/default/files/Guide_SMB_ES_int eractive_eBay.pdf

[20] FEIQUE - Federación Empresarial de la Industria Química Española. Radiografía Económica del Sector Químico Español. 2016. www.feique.org/pdfs/Radiografia_Economica_del_sector_2016.pdf

[21] FEIQUE - Federación Empresarial de la Industria Química Española. Nota de prensa - FEIQUE hace entrega de sus I Premios RSE a 17 empresas del sector químico. 2015. http://www.feique.org/wpcontent/uploads/2017/02/12-10-NdP-Feique-entrega-sus-I-PremiosRSE-a-17-companias-del-sector-quimico.pdf

[22] DHL News. Premios DHL ATLAS a la exportación. 2015. http://www.premiosdhlatlas.com/\#anteriores
[23] DMOZ. Available in: http://www.dmoz.org/

[24] Expansión. Available in: http://www.expansion.com/empresasde/buscadorEmpresas.html

[25] A. Chua, D. GOH and R. ANG. Web 2.0 application in governmen web sites: Prevalecence use and correlotaions with perceived web site quality. Journal Information Review, 175-195, 2012.

[26] J. Gutiérrez-Artacho and M.D. Olvera-Lobo, M.D. Web localization as an essential factor in the internationalisation of companies: an approximation of Spanish SMEs. WorldCist' 17 - 5th World Conference on Information Systems and Technologies, 2017. 